\title{
COMMENTARY ON "POSSIBLE EFFECTS ON OCCUPATIONAL LUNG CANCER FROM SMOKING RELATED CHANGES IN THE MUCUS CONTENT OF THE LUNG",
}

\author{
I. T. T. Higgins \\ Department of Epidemiology, School of Public Health, The University of Michigan, Ann Arbor, \\ MI 48109, U.S.A.
}

(Rereined 22 Nowember 1982)

THE HYPOTHESIS that smoking may protect workers from the adverse consequences of inhaling dusts, fumes or gases on the job is an interesting one. As Sterling points out, workers in dusty occupations do sometimes claim that they smoke because smoking helps them to get rid of the dust from their lungs. And doctors have on occasion been known to support this view. In the 1950s in Britain, it was found that elderly coal miners without radiographic evidence of dust in the lungs were sometimes more likely to be disabled than miners of comparable age with the most advanced stage of simple pneumoconiosis. The hypothesis was entertained that this might have been due to cigarette smoking causing bronchitis, which protected the lungs from pneumoconiosis but which resulted in obstructive airways disease and consequent disability. In the present paper, the focus is on lung cancer. Sterling advances the hypothesis that smoking by increasing the mucus content of the lung reduces the impact of respiratory carcinogens. The pathological concept is of a layer of mucus lining the respiratory passages, which either blocks the access of the carcinogens to the mucus membrane, or dilutes and clears them more effectively than normal.

Three kinds of evidence are advanced to support this hypothesis. First, studies are cited that indicate that the lung dust burden is less in smokers than in non-smokers. Second, certain epidemiological studies have shown or been reported to show a higher risk of lung cancer in workers exposed to respiratory carcinogens who do not smoke compared to those who do. Third, an experimental study on Beagle dogs is quoted to support the contention that the incidence of cancers in the respiratory tract is greater in animals exposed to carcinogenic dusts alone than in animals exposed to carcinogenic dusts and cigarette smoke. I should like to comment on these studies.

The study by Pinto et al. [1] on pensioners from a copper smelter, who had been exposed at work to arsenic was of particular interest to me, since, for the past few years, my colleagues and I have becn trying to disentangle the relative importance of exposure to arsenic trioxide and smoking in the cause of lung cancer among smelter workers. Table 1 (Table 3 from Pinto's paper), shows the appropriate comparison. It will be seen that the number of cancer cases was small-only 3 among the non-smokers and 3 more among the

\begin{tabular}{|c|c|c|c|}
\hline & ING CATEGORY & IN PENSIONERS & \\
\hline & $\begin{array}{c}\text { No. of } \\
\text { pensioners }\end{array}$ & $\begin{array}{l}\text { Deaths from } \\
\text { lung cancer }\end{array}$ & SMR \\
\hline Smokers & 189 & 15 & 287 \\
\hline Ex-smokers & 69 & 3 & 245 \\
\hline Non-smokers & 119 & 3 & 507 \\
\hline
\end{tabular}




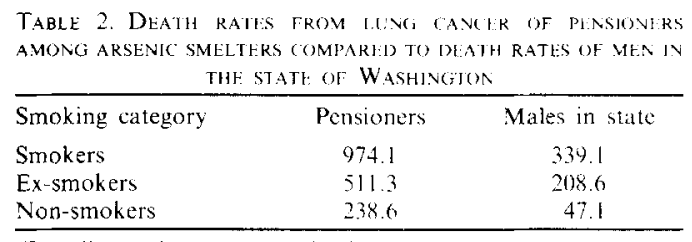

(Enterline. private communication.)

ex-smokers. The authors also observed that "while the differenees among the three groupings are not statistically significant, there is evidence of a negative interaction for SMRs but a positive interaction if the excess in respiratory cancer is expressed as an absolute rather than a relative risk." Dr Enterline has kindly provided me with the information presented in Table 2. The table shows lung cancer death rates by smoking categories for the pensioners and for comparison lung cancer death rates for men of similar age in the State of Washington. The rates for smokers are as one would expect higher than those of non-smokers. Clearly, it makes a big difference to the conclusions one might draw about the benefits of smoking whether one uses relative or absolute risk.

Table 3 presents information on the mortality from lung cancer in a sample of the 1800 smelter workers in our study according to estimated exposure to arsenic and smoking habits (Welch et al., 1982). The table shows standardized mortality ratios according to estimated time weighted exposure to arsenic for smokers and non-smokers. Clearly the table provides no support for the view that cigarette smoking is prophylactic for respiratory cancer. It is, however, surprising that smoking appears to be a relatively unimportant factor in the lung cancer mortality of this group of workers.

The second study purporting to show higher lung cancer death rates among nonsmokers than smokers is the study of zinc-lead miners in Sweden (Axelson and Sundell [2]). This is a difficult study to interpret.

It was a case-referent study. The cases comprised 29 men who died of lung cancer in the parish of Hammer (population 4000), between 1956 and 1976. The comparison group consisted of the three men entered in the registry before and after each case, who died an accidental death or from any disease other than lung cancer. Unfortunately, this method of selecting a comparison group resulted in one which differed strikingly from the lung cancer cases in respect to age. Table 4 (derived from Table 2 of their paper). shows that the lung cancer cases were much younger than the referents. In fact, $45 \%$ of the referents but only $7 \%$ of the lung cancer cases were $80 \mathrm{yr}$ and over. Furthermore, conclusions about smoking were based on only 19 miners. Table 5 of their paper (not presented), shows that the mean age at death of the 9 non-smokers $(70.4 \mathrm{yr})$ was $11.1 \mathrm{yr}$ greater than that of the 10 smokers $(59.3 \mathrm{yr})$. In passing, one might wonder about the categorization of the smoking habits and particularly the nearly equal proportions of non-smokers and smokers.

\begin{tabular}{|c|c|c|c|c|c|}
\hline \multirow{2}{*}{$\begin{array}{l}\text { Arsenic } \\
\text { category } \\
\left(t a \mathrm{~g} / \mathrm{m}^{3}\right)\end{array}$} & \multirow[b]{2}{*}{ Smoking habits } & \multicolumn{4}{|c|}{ Time neighted averagc } \\
\hline & & $N$ & Obs & Exp & SMR \\
\hline \multirow{3}{*}{$\begin{array}{l}\text { Low } \\
\qquad(<100)\end{array}$} & Smokers & 362 & f & $5 . x$ & 120 \\
\hline & Cigarette & 333 & 7 & 5.3 & 132 \\
\hline & Nonsmokers & 72 & 1 & 1.1 & 95 \\
\hline \multirow{3}{*}{$\begin{array}{l}\text { Medium } \\
\qquad(100-499)\end{array}$} & Smokers & 364 & 16 & 5.1 & $312^{* *}$ \\
\hline & Cigarette & 329 & 14 & 4.7 & $296^{* *}$ \\
\hline & Nonsmokers & 71 & 1 & 1.1 & 89 \\
\hline \multirow{3}{*}{$\begin{array}{l}\text { High } \\
\qquad(500.4999)\end{array}$} & Smokers & 386 & 20 & 5.6 & $359 * *$ \\
\hline & Cigarette & $33 x$ & 18 & 4.8 & $372 * *$ \\
\hline & Nonsmokers & 77 & 4 & 1.4 & 286 \\
\hline \multirow{3}{*}{$\begin{array}{l}\text { Very high } \\
(\geqslant 5000)\end{array}$} & Smokers & 104 & 16 & 2.0 & $803^{* *}$ \\
\hline & Cigarette & 91 & 15 & 1.6 & $910^{* *}$ \\
\hline & Nonsmokers & 20 & 2 & 0.3 & 620 \\
\hline
\end{tabular}

*Significant at 0.05 level; **Significant at 0.01 level 


\begin{tabular}{|c|c|c|c|c|}
\hline \multirow{3}{*}{$\begin{array}{l}\text { Age } \\
(y \mathbf{r})\end{array}$} & \multirow{2}{*}{\multicolumn{2}{|c|}{ Lung cancer cases }} & \multicolumn{2}{|c|}{ Referents } \\
\hline & & & & \\
\hline & $N$ & $\because$ & $N$ & $\%$ \\
\hline 50 & 1 & 3 & 7 & 4 \\
\hline $50-$ & 8 & 28 & 12 & 7 \\
\hline $60-$ & 10 & 34 & 31 & 18 \\
\hline $70-$ & 8 & 28 & 45 & 26 \\
\hline $80+$ & 2 & 7 & 79 & 45 \\
\hline$T_{0}[\mathrm{a}]$ & 29 & 100 & 174 & 99 \\
\hline
\end{tabular}

This would not be characteristic of the U.K. or the U.S., though I suppose it could be true of rural Sweden over the time covered by this study. In view of the small numbers and these large differences in age, it would seem to be extremely hazardous to draw any conclusions about these groups. I should be reluctant even to accept the author's cautious statement that "among these miners, non-smokers seem to be more apt to develop lung cancer than smokers", especially when it is coupled with the apparent paradox "whereas, after induction, lung cancer develops more quickly among smokers."

The study by Weiss [3] does, however provide some support for the view that in workers exposed to a powerful respiratory carcinogen the risk of developing lung cancer may sometimes be greater in non-smokers than in smokers. The study comprised 51 men who were moderately to heavily exposed to chloromethyl ether, for whom smoking habits had been recorded. Mortality rates from lung cancer between 1963 and 1972 according to smoking habits in 1963 were compared with expectations based on Dorn's study of verterans. Table 5 (Table 1 from Weiss's paper) presents the findings. Whatever else the table shows, it is clear that exposure to CME poses a serious hazard of respiratory cancer. Whether the SMRs are appropriate for evaluating smoking is perhaps debatable. But even if one merely relates the deaths to the man-years of observation it is clear that the non-smokers and ex-smokers were at a relative disadvantage compared with the smokers.

Sterling quotes the results of an experiment in beagle dogs [4] which he claims supports the idea of a mitigating effect of tobacco smoke on the production of respiratory cancers by radon, radon daughters and uranium dust. In two of four experimental groups, a comparison was made of the number of cancers that developed depending on whether or not the dogs were exposed to tobacco smoke as well as to ionizing radiation. At first sight the difference in the number of dogs developing cancer, 2 in the smoking groups compared with 8 (one dog developed 2 cancers) in the non-smoking group, is striking. Careful evaluation, however, shows that the age at death of the non-smoking dogs (and presumably as a consequence of this), their cumulative radon exposure in working level months was somewhat greater than that of the smoking dogs. Since the development of cancer was strongly related to age and dosage, it would seem to be unwise to read too much into this experiment. In passing I might note that the authors of this study cited a study in rats [5], which found tobacco smoke to be co-carcinogenic with radon daughters. Sterling, however, does not comment on this piece of evidence against his hypothesis.

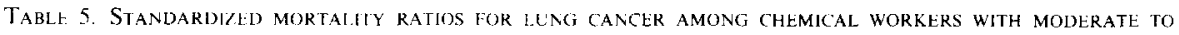
HEAVY CUMCLATIVE EXPOSURI: TO CME. 1963-1972, BY CIGARETTE SMOKING HABIT IN 1963

\begin{tabular}{lcccccc}
\hline & \multicolumn{5}{c}{ Lung cancer } \\
Cigaretie smoking habit & No. of men man-years & No. & No. & SMR & $p^{+}$ \\
Non-smokers and ex-smokers & 13 & 112 & 6 & 0.00222 & 2703 & $<0.001$ \\
Current & 38 & 353 & 5 & 0.14090 & 35 & $<0.001$ \\
$<1$ pk. per day & 28 & 262 & 4 & 0.08295 & 48 & $<0.001$ \\
I+ pks per day & 10 & 91 & 1 & 0.05795 & 17 & $>0.05$ \\
Total & 51 & 463 & 11 & 0.14312 & 77 & $<0.001$ \\
\hline
\end{tabular}

*Using rates from the Dorn study of smoking and mortality among U.S. veterans by Kahn.

tUsing confidence limits for the expectation of a Poisson variable.

(Reproduced with kind permission from Weiss, 1980.) 
All in all, the evidence presented by Sterling to support his hypothesis is less than convincing. I do, however, agree with him on one suggestion, namely that more information is needed on the relative importance of smoking and occupation in the causation of lung cancer. In particular, we need to know more than we do at present about the interaction of these two factors in the dozen or so well recognized occupational causes of lung cancer.

In conclusion, it is to be hoped that no one will be encouraged to smoke in order to reduce the risk of lung cancer from any occupational carcinogen. The evidence on balance is overwhelmingly against smoking as the most important cause of lung cancer, not to mention its important role in the genesis of obstructive airways disease. Excess mucus in the lungs is a condition to be rigorously avoided by any possible means.

\section{REFERENCES}

1. Pinto SS, Henderson V, Enterline PE: Mortality experience of arsenic-exposed workers. Arch Envir Hlth 33: 325,1978

2. Axelson O, Sundell I et al: Mining, smoking and lung cancer. Scand J Work Envir Hlth 4l: 46, 1978

3. Weiss W: The cigarette factor in lung cancer due to chloromethyl ethers. J Occup Med 22: $52 \%$, 1980

4. Cross FT, Palmer RF, Filipy RE, Dagle GE, Stuart BO: Carcinogenic effects of radon daughters, uranium ore dust and cigarette smoke in beagle dogs. Health Phys 42: 33-52, 1982

5. Chameaud J, Perraud R, Masse R, Nenot JC, Lafuma J: Cancers du Poumon Provoques chez le Rat par le Radon et Ses Descendants a Diverses Concentrations. Paper No. IAEA-SM-202/410. Proc IAEA, Chicago, 1977

6. Welch $\mathrm{K}$, Higgins I, Oh M, Burchfiel C: Arsenic exposure, smoking and respiratory cancer in copper smelter workers. Arch Envir Hlth 37: 325-335, 1982 